\section{Impaired acquisition of a simultaneous brightness discrimination by cortically and hippocampally lesioned rats*}

\author{
MICHAEL L. WOODRUFF, BARBARA SCHNEIDERMAN \\ and ROBERT L. ISAACSON \\ University of Florida, Gainesville, Fla. 32601
}

Rats with neocortical and hippocampal lesions, as well as normal animals, were trained in a visual discrimination task. The periods of stimulus presentation indicating the "correct lever" were separated by 10 -sec intertrial intervals. Both lesion groups were impaired in the acquisition of the problem, but only the animals with hippocampal damage evidenced significantly higher response rates during the intertrial intervals.

In two-choice maze sitautions, hippocampal lesions in rats and cats produce deficits in the acquisition of a successive discrimination task (Kimble, 1963; Niki, 1965; Buerger, 1969), but it has been reported that the acquisition of a simple simultaneous discrimination is not impaired by this lesion (Kimble, 1963; Kimble \& Kimble, 1965, 1970; Douglas, 1967). However, Woodruff \& Isaacson (ii. press) found that bilaterally hippocampectomized animals were deficient in the acquisition of a visual discrimination in an operant task. In addition, Means, Woodruff, and Isaacson $^{1}$ found that animals with hippocampal destruction were deficient in the acquisition of a visual discrimination using a go, no-go procedure. In passing, it should be mentioned that this type of behavioral paradigm is one in which animals with hippocampal destruction are facilitated when acquiring a single alternation task (Walker et al, 1970).

The purpose of the present study was to replicate the results of Woodruff and Isaacson ${ }^{1}$, using a different strain of rats, while giving special attention to the responding of the lesioned animals in the intertrial intervals. In the experimental paradigm employed, the animal could learn (1) to discriminate the rewarded and nonrewarded levers on the basis of the signal light provided and (2) not to respond during the intertrial intervals which were essentially "time-out" periods.

\section{METHOD}

Thirty naive male Long-Evans (hooded) rats, ranging in weight from 330 to $410 \mathrm{~g}$ at the beginning of the experiment, were divided into three

* This research was supported in part by Grant NIMH 16384-03 to $R$. L. Isaacson. Mr. Woodruff receives support from USPHS Training Grant MH-10320 to the Center for Neurobiological Sciences, University of Florida. groups. The 10 rats of Group 1 received bilateral aspiration lesions of the hippocampus, while the 10 rats of Group 2 received bilateral aspiration lesions of the dorsolateral cortex overlying the hippocampus. The 10 rats in Group 3 served as unoperated controls. The surgical techniques employed in this experiment have been described in detail elsewhere (Isaacson et al, 1961). Briefly, all surgery was performed in one stage under sodium pentobarbital anesthesia $(50 \mathrm{mg} / \mathrm{kg}$, IP). After anesthetization, a midline incision was made in the scalp of animals in Groups 1 and 2 . The scalp was retracted and the neocortex exposed using a dental burr and rongeurs. The neocortex was removed, exposing the hippocampus bilaterally.

At this point, surgery was concluded for the animals of Group 2. The hippocampus was also removed under visual guidance for the animals in Group 1. Fourteen days following surgery, the animals were placed on food deprivation until they reached $85 \%$ of their ad lib body weight. When all animals had obtained their target weights, barpress training was begun.

Training was conducted in a two-bar Grason-Stadler (Model E3125B-100) operant chamber, which discharged a $45-\mathrm{mg}$ food pellet as reinforcement. The chamber was enclosed in a sound-attenuating chamber (Grason-Stadler Model 3125 AA-3). The ventilation fan provided a continuous masking noise. Electromechanical timers and relays controlled the presentation of stimuli and reinforcements. Counters recorded response latencies and barpresses. The Ss were trained on a continuous reinforcement schedule (CRF) for $1 / 2 \mathrm{~h}$ a day for 7 days before being placed on discrimination training. At the end of this time, all rats were pressing both bars at a steady rate. On the 26th postoperative day, the brightness discrimination was begun. Each $\mathrm{S}$ was trained for $30 \mathrm{~min}$ a day for 14 days. The discrimination paradigm was programmed such that at the beginning of each trial a stimulus light $\left(\mathrm{S}_{\mathrm{D}}\right)$ was illuminated over the bar that would be reinforced. If the $\mathbf{S}$ made a reinforced response, the selection of the bar over which the $S_{D}$ would appear was randomly determined. If the $S$ made an incorrect response, the $S_{D}$ remained over the same bar on all subsequent trials until a correct response was made. Following every response, the $S_{D}$ was terminated and a 10-sec intertrial interval ensued. No other changes in the experimental situation were made in the ITI period.

At the conclusion of training, each operated $S$ was sacrificed and intracardially perfused with $0.9 \%$ saline followed by $10 \%$ formalin. The brain was removed, embedded in celloidin, and sectioned at 30 microns; every 10th section was retained, slide-mounted, and stained with thionin.

\section{RESULTS}

Examination of the histology revealed that the hippocampal lesions produced in the $\mathrm{Ss}$ in Group 1 were similar to those generally reported, particularly to those made by Woodruff \& Isaacson (in press). Virtually the entire dorsal and lateral aspects of the hippocampus were removed bilaterally, with a varying amount of the ventral portion of the structure being spared. The neocortex overlying the hippocampus was ablated in all animals in this group. The amount of cortex removed from the control Ss in Group 2 was similar to that removed in the animals with hippocampal damage. Gliosis and necrosis of cells in the lateral geniculate and lateral nuclei were seen in the thalamus in 8 of the 10 cortical Ss and in 7 of the 10 hippocampal Ss. This was attributed to retrograde degeneration caused by destruction of varying amounts of the neocortex. However, the presence or absence of this destruction was not correlated with performance on the discrimination task.

The mean number of responses made by the three groups during the ITI periods for Days 1-14 is presented in Fig. 1A. From this figure it can be seen that the hippocampally ablated group made many more responses during the ITIs than did either the cortically ablated or normal control groups. A two-way analysis of variance with one repeated measure indicated a statistically significant difference among groups $(\mathrm{F}=7.14, \mathrm{df}=2,25$, $\mathrm{p}<.01$ ), and a subsequent Newman-Keuls analysis revealed that the hippocampectomized rats had more ITI responses than either the cortically ablated group $(p<.05)$ or the normal group $(p<.01)$. These 

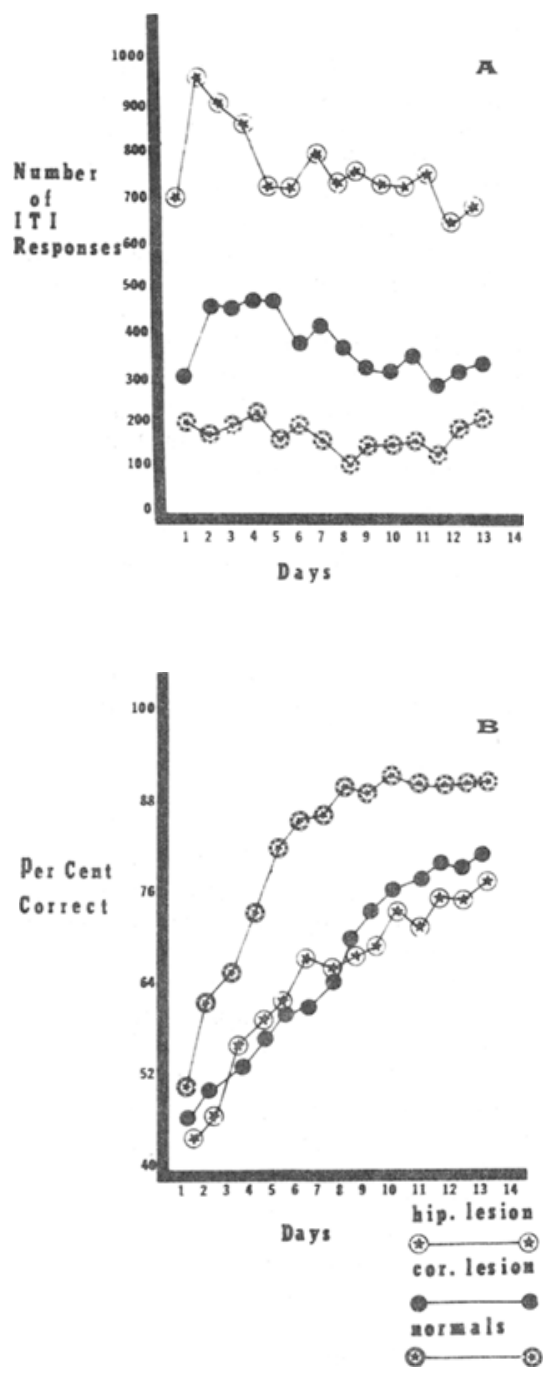

Fig. 1. (A) Daily mean number of intertrial interval responses made by each group, during discrimination training. (B) Daily mean percent correct responses made by each group during discrimination training.

groups did not differ from one another. There was no significant change in the number of ITI responses for any group over days.

A two-way analysis of variance with one repeated measure was also performed on the mean percent correct responses made by the $\mathrm{Ss}$ in each group for each day. A significant difference appeared $(\mathrm{F}=12.74, \mathrm{df}=$ $2,25, \quad \mathrm{p}<.01)$. A Newman-Keuls analysis showed that the normal control group made more correct responses than either of the two lesioned groups $(p<.01)$. There was also a significant increase in the number of correct responses for all groups across days, but there was not a significant Lesion by Days interaction. The daily mean percent correct for each group is presented in Fig. 1B.

\section{DISCUSSION}

The results of the present study replicate those of Woodruff and Isaacson (in press) to the extent that the hippocampally ablated rats were found to be deficient in the acquisition of a simultaneous operant discrimination task. However, contrary to the report of Woodruff and Isaacson, the neocortically lesioned control rats also exhibited a deficit in the acquisition of this task. The deficit in acquisition found in the rats belonging to the neocortically ablated group is surprising in light of reports that lesions of visual cortex do not affect acquisition of a brightness discrimination (e.g., Lashley, 1935; Horel et al, 1966). However, Lewellyn et al (1969) also found that posterior cortical lesions produced a deficit in the acquisition of a brightness discrimination by rats based upon food rewards. It may be that the use of a task in which food is the reinforcer is a factor in producing the deficit. For example, Lashley (1935) and Horel et al (1966) used tasks in which a correct response allowed Ss to avoid shock. Krechevsky (1936) has shown that posterior cortical lesions produce deficits in learning a brightness task only when the animals are not shocked after an incorrect response. Thompson and his colleagues have presented evidence that two visual systems may exist in the rat which subserve visual behaviors based on positive and negative incentive systems (Thompson, Rich, \& Langer, 1964).

Strain differences may help explain the difference in the effect of neocortical lesions found in this study and in that of Woodruff and Isaacson (in press). In the previous study, Woodruff and Isaacson used albino rats as Ss, whereas hooded rats of the Long-Evans strain were used in the present study. Another difference between the present study and the studies of Lashley and of Horel et al is that in the latter study the rate of response was E-controlled, while in the present study and in that by Lewellyn et al (1969), the rate of response was $S$ controlled. Since it has been found that posterior cortically lesioned rats were more active than normals (Altman, 1962; Schmaltz \& Isaacson, 1966) and also that they respond at a higher rate in an operant task (Lewellyn et al, 1969), it might be thought that the cortically ablated Ss maintained a higher rate of response and that this contributed to the deficit. However, the number of ITI responses of the cortically lesioned group was not significantly greater than that of control animals in the present study.

The hippocampectomized group demonstrated a much higher rate of ITI responding than either of the other groups, though it is interesting to note that none of the groups showed any decrease in ITI responding across training days. The finding of increased rates of responding by hippocampectomized rats on a partial reinforcement schedule is in agreement with the results of other authors (Jarrard, 1965; Schmaltz \& Isaacson, 1966). Apparently, the deficits in performance in terms of percent correct responses can be dissociated from the enhanced rates of responding during the ITI. The cortically lesioned animals evidenced impaired acquisition of the problem but failed to show a significantly enhanced number of ITI responses. If it is argued that the much greater ITI responding prevented the animals with hippocampal lesions from giving adequate attention to the visual signal, another explanation must be provided for the deficit of the neocortically lesioned animals.

\section{REFERENCES}

ALTMAN, J. Effects of lesions in central nervous visual structures on light aversion of rats. American Journal of Physiology, 1962, 202, 1208-1210.

BUERGER, A. A. Impaired acquisition of a successive visual pattern discrimination following hippocampal ablations in cats. Psychonomic Science, 1969, 15, 225-226. DOUGLAS, R. J. The hippocampus and behavior. Psychological Bulletin, 1967, $67,416-442$.

HOREL, J. A., BETLINGER, L. A., ROYCE, G. J., \& MEYER, D. R. Role of neocortex in the learning and relearning of two visual habits by the rat. Journal of Comparative \& Physiological Psychology. $1966,61,66-78$.

ISAACSON, R. L., DOUGLAS, R. J., \& MOORE, $R$. $Y$. The effect of radical hippocampal ablation on acquisition of avoidance response. Journal of Comparative \& Physiological Psy chology, $1961,54,625-628$.

JARRARD, L. E. Hippocampal ablation and operant behavior in the rat. Psychonomic Science, 1965, 2, 115-116.

KIMBLE, D. P. The effects of bilateral hippocampal lesions in rats. Journal of Comparative \& Physiological Psychology, 1963, 56, 273-283.

KIMBLE, D. P., \& KIMBLE, R. J. $\mathrm{Hippocampectomy} \mathrm{and} \mathrm{response}$ perseveration in the rat. Journal of Comparative \& Physiological Psychology. $1965,60,474-476$.

KIMBLE, D. P.. \& KIMBLE, R. J. The effect of hippocampal lesions on extinction and "hypothesis" behavior in rats. Physiology \& Behavior, 1970,5 , 735-738.

KRECHEVSKY, I. Brain mechanisms and brightness discrimination learning. Journal of Comparative Psychology, $1936,21,404-445$.

LASHLEY, K. S. The mechanism of vision: XII. Nervous structures concerned in the acquisition and retention of habits based on reactions to light. Comparative Psychology Monograph, 1935. 11 .

LEWELLYN, D. IOWES. G.. \& ISAACSON, R. L. Visually mediated behaviors following neocortical destruction in the rat. Journal of Comparative \& Physiological Psychology, $1969,69,25-32$.

NIKI, $H$. The effects of hippocampal ablation on the inhibitory control of 
operant behavior in the rat. Japanese Psychological Research, 1965, 7, 126-137.

SCHMALTZ, L., \& ISAACSON, R. L. The effects of preliminary training conditions under DRL performance in the hippocampectomized rat. Physiology \& hehavior, 1966,1,175-182.

THOMPSON, R., RICH, I., \& LANGER, S. $K$. Lesion studies on the functional significance of the posterior thalamo-mesencephalic tract. Journal o1 Comparative Neurology, 1964,123 29-44.

WALKER, D. W., MEANS, L. W., \& ISAACSON, $R$. L. The effects of hippocampal and cortical lesions on single alternation go, no-go acquisition in rats. Psy chonomic Science, 1970, 21, 29-31. WOODRUFF, M. L. \& ISAACSON, R. L
Discrimination learning in rats with lesions of hippocampus. Behavioral Biology, in press.

$$
\text { NOTE }
$$

1. Means, L. W., Woodruff, M. L., \& I saacson, R. L. Deficient go, no-go brightness discrimination in rats following hippocampal lesions, in preparation. 